УДК 94(470.6)»1930»

ГАДИЦКАЯ Марина Александровна - кандидат исторических наук, доцент кафедры всеобщей истории историко-филологического факультета Сочинского института - филиала Российского университета дружбы народов (354348, Россия, Краснодарский край, г. Сочи, Адлерский р-н, ул. Куйбышева, 32; marinagaditskay@mail.ru)

\title{
МОТОЦИКЛЫ И ВЕЛОСИПЕДЫ КАК НОВЫЕ СРЕДСТВА ПЕРЕДВИЖЕНИЯ В ПОВСЕДНЕВНОСТИ ЮЖНОРОССИЙСКИХ КОЛХОЗНИКОВ 1930-х гг.
}

Аннотация. В статье раскрывается один из знаковых сюжетов сельской повседневности периода колхозного строительства, когда в деревне появляются в массовом порядке ранее не характерные средства передвижения - мотоциклы и велосипеды. Приводятся количественные и качественные показатели процесса «бытовой механизации» среди колхозников Юга России, в частности, описываются марки отечественных мотоциклов и велосипедов 1930-х гг. Подчеркивается общая тенденция роста покупательной способности сельского населения, имевшего возможность при сложившемся порядке цен приобретать мотоциклы и велосипеды. Раскрывается отношение колхозников к новой технике, все более основательно входившей в сельскую повседневность.

Ключевые слова: велосипеды, дефицит, колхозники, механизаторы, мотоциклы, повседневность, цена техники

$\mathrm{P}$ азвернувшиеся в СССР в 1930-х гг. индустриализация и механизация аграрного производства, являвшиеся одним из важнейших мероприятий сплошной коллективизации, оказали существенное воздействие не только на сельское хозяйство, но и на повседневную жизнь населения советской деревни. Процесс механизации деревенской обыденности не был гладким и стремительным, но мотоциклы и велосипеды стали зримой и весомой частью сельского быта, фактором и особенностью «бытовой механизации».

Мотоциклы появились в России еще в досоветский период, причем основная масса мотоциклов (или, как тогда говорили, мотоциклетов) завозилась из-за рубежа: из Англии, Германии, Франции, США. Предпринимались попытки изготавливать и собственные мотоциклы, к примеру, небольшие партии выпускали: расположенная в Риге компания «А. Лейтнер и $\mathrm{K}^{\circ}$ » (мотор-велосипеды марки «Россия»), действовавшая в Санкт-Петербурге экипажная фабрика «Фрезе», московская фабрика «Дукс» (затем - «Дукс Ю.А. Меллер»)1. Во время Первой мировой войны численность мотоциклов иностранного производства увеличилась за счет новых поставок для удовлетворения возросших потребностей армии. В частности, Англия поставляла мотоцикл Royal Enfield 8 HP (мощностью 8 л.с.) с конструктивно усиленной рамой, называвшийся «колониальной моделью».

По окончании Первой мировой и Гражданской войн на территории Советской России оказалось немало образцов и экземпляров мототехники. Кроме того, в 1920-х гг. возобновился импорт «моторных двухколесок», чем занималась государственная организация «Автопромторг» 2 . Но советские специалисты стремились создать модели отечественных мотоциклов и наладить их массовый выпуск. В начале 1924 г. инициативная группа инженеров московского завода

\footnotetext{
${ }^{1}$ Курихин О.В. Самые первые. - Техника - молодежи. 1989. № 1. С. 23.

2 Курихин О.В. «Союз». - Техника - молодежи. 1989. № 2. С. 23.
} 
ОСОАВИАХИМ-1 (бывший «Дукс») спроектировала первый советский мотоцикл «Союз». Тем не менее в целом по СССР к началу 1928 г. насчитывалось лишь 6305 мотоциклов, или не более 0,3\% мирового парка1.

В условиях индустриализации многократно увеличилась численность мотоциклов отечественного производства. На ленинградском заводе «Красный Октябрь» в 1930-х гг. произвели 18985 экземпляров мототехники Л-300 «Красный Октябрь» - первого серийного мотоцикла ${ }^{2}$. На Таганрогском инструментальном заводе № 65 к 1 мая 1935 г. на основе английского мотоцикла BSA Sloper-600 спроектировали и собрали три образца собственного изделия ТИЗ-АМ-600 мощностью 16,5 л.с. - самого мощного на тот момент в стране. С 1936 г. в Таганроге началось его серийное производство ${ }^{3}$. Всего изготовили 3006 экземпляров ТИЗ-АМ-6004. Во второй половине 1939 г. на Серпуховском механическом заводе пошел в тираж советский мотоцикл легкого класса МЛ-3 для поездок по пересеченной местности и бездорожью ${ }^{5}$. В начале 1930 -х гг. комиссия ВСНХ СССР во главе с В.В. Куйбышевым приняла решение построить в Ижевске завод-гигант с объемом производства 120 тыс. мотоциклов в год ${ }^{6}$. В 1934 г. началось изготовление первого серийного ижевского мотоцикла ИЖ-7 (было изготовлено 5581 шт.), а с 1938 г. выпускался ИЖ-8 (9 893 шт.). В 1940 г. на конвейер поставили ИЖ-9 (6 225 шт.) ${ }^{7}$.

Мотоциклы, в отличие от автомобилей, были сравнительно легки в производстве и дешевы. Поэтому в 1930-х гг. у сельских жителей, в т.Ч. Юга России, существовали вполне осязаемые возможности их приобрести. В первых рядах здесь шли передовики и ударники производства, особенно из числа механизаторов. Именно они не только располагали финансами для покупки индивидуального транспортного средства, но и в массе своей любили и ценили технику и имели необходимые для ее эксплуатации знания и навыки. Так, в начале 1939 г. тракторист-комбайнер Юловского зерносовхоза Ростовской области Г.С. Нестеренко с удовлетворением говорил, что за время уборочной кампании получил 8 тыс. руб. и потому «обзавелся собственным мотоциклом, о котором даже понятия не имели не только мои родители, но и вообще в дореволюционной деревне» 8 .

В отличие от предшествующих десятилетий, в 1930-х гг. в городах и селах, в т.ч. на Юге России, решительно преобладали мотоциклы отечественного производства. Это стало закономерным и отрадным результатом индустриализации, позволившей выпускать отечественную технику уже не мизерными партиями в десятки или сотни экземпляров, а тысячными сериями. На фотографиях, в кинохронике и художественных фильмах 1930-х гг. мы видим, как правило, отечественные мотоциклы. Так, героиня известного фильма «Трактористы» (снят в 1939 г., режиссер И.А. Пырьев) - бригадир тракторной бригады, кавалер ордена Трудового Красного Знамени Марьяна Бажан (эту роль исполняет актриса М.А. Ладынина) - ездит на мотоцикле марки ПМЗ-А-750. Этот тяжелый советский мотоцикл разработали сотрудники Научного автотракторного института (НАТИ) на основе модели американской фирмы «Харлей-Дэвидсон».

\footnotetext{
1 Курихин О.В. «Великолепная пятерка». - Техника - молодежи. 1989. № 3. С. 19.

2 Кириндас А.М., Ксенофонтов И.В. Мотоциклы в военной форме. - Техника и вооружение. 2014. № 7. С. 15 .

3 Курихин О.В. В поисках прототипа. - Техника - молодежи. 1989. № 7. С. 21.

4 Кириндас А.М., Ксенофонтов И.В. Мотоциклы в военной форме. - Техника и вооружение. 2014. № 7. С. 15 .

5 Курихин О.В. Легкие мотоциклы. - Техника - молодежи. 1989. № 9. С. 19.

6 Курихин О.В. В серии тяжелые. - Техника - молодежи. 1989. № 5. С. 19.

7 Кириндас А.М., Ксенофонтов И.В. Мотоциклы в военной форме. - Техника и вооружение. 2014. № 7. С. 15 .

8 Нестеренко Г.С. Труд стал радостью. - Тракторист и комбайнер. 1939. № 2. С. 6.
} 
Первоначально он назывался в честь разработчика (НАТИ-А-750), но затем техническую документацию передали Подольскому механическому заводу, где с марта 1934 г. и началось массовое производство этих машин. После этого мотоцикл получил новое наименование - ПМЗ-А-7501. В советской комедии «Сердца четырех» (снята в 1941 г., до начала Великой Отечественной войны, режиссер К.К. Юдин) можно увидеть первый советский серийный мотоцикл Л-300 «Красный Октябрь». На нем ездит один из героев фильма старший лейтенант Петр Колчин (его роль исполняет артист Е.В. Самойлов).

Вместе с тем даже во второй половине 1930-х гг. в СССР эксплуатировались мотоциклы иностранного производства, причем выпущенные на зарубежных заводах еще до 1917 г. На одной из фотографий в журнале «Колхозница» за 1937 г. запечатлен знатный комбайнер Трофим Костенко из Азово-Черноморского края, опирающийся на руль мотоцикла 2 . На фотографии хорошо видна лишь передняя часть машины: стойка передней вилки и передняя часть топливного бака. Ни стойка, снабженная двумя мощными пружинами, ни прямоугольный топливный бак не позволяют считать мотоцикл Т. Костенко советским, поскольку отечественные модели выглядели совершенно иначе. Каково же было удивление автора настоящей статьи, когда после активных поисков удалось установить, что на фото запечатлен упоминавшийся выше Royal Enfield 8 HP - «колониальная модель» с усиленной рамой, поставлявшаяся в Российскую империю во время Первой мировой войны!

Говоря о велосипедах, отметим их появление в России, как и мотоциклов, еще в досоветский период. Они также импортировались из зарубежных государств - Англии, Германии, Франции. Активно работали над значительным увеличением объемов выпуска двухколесной машины и отечественные производители - все те же «А. Лейтнер и $\mathrm{K}^{\circ} »$ и «Дукс» («Дукс Ю.А. Меллер»). Но и мотоциклы, и велосипеды в то время являлись привилегией горожан, а основная масса сельских жителей о них не имела ни малейшего представления.

В 1930-х гг. в СССР развернулось промышленное производство собственных велосипедов на целом ряде предприятий, в т.ч. на заводе «Ленинградский металлист», Московском велосипедном заводе (МВ3) и др. В частности, на МВ3 изготавливали дорожный велосипед МД-1 (мужской дорожный); с 1936 г. завод приступил к выпуску первой гоночной модели советского велосипеда ГМ-30. Объемы производства велосипедов выросли во второй половине 1930-х гг., когда советская промышленность в основном преодолела болезни роста и сумела реализовать потенциал, заложенный во время индустриализации. По статистике в 1937 г. в СССР промышленность выпустила велосипедов в 4,2 раза больше, чем в 1932 г. [Хейнман 1939: 67].

Неоспоримым достоинством и преимуществом велосипедов в сравнении с мотоциклами являлись простота в изготовлении и эксплуатации, а также относительная дешевизна. Судя по лотерейным билетам 3-й Всесоюзной лотереи Осоавиахима (июнь 1929 г.), велосипед стоил 200 руб., а мотоцикл (без указания модели и марки) - 1200 руб. В билетах 14-й лотереи Осоавиахима (ноябрь 1940 г.) цена обычного дорожного велосипеда составляла 500 руб., детского велосипеда - 150 руб. (при цене дамской сумки в 100 руб.), а мотоцикл с коляской оценивался в 8000 руб., мотоцикл без коляски - в 3500 руб.

Все это превращало велосипед в ходовой потребительский товар, популярный и востребованный колхозным крестьянством. Так, в сентябре 1934 г. секретарь Благодарненского райкома ВКП(б) Северо-Кавказского края Лобакин заяв-

\footnotetext{
${ }_{1}^{1}$ Курихин О.В. В серии тяжелые. - Техника - молодежи. 1989. № 5. С. 19.

2 Колхозница. 1937. № 8-9. С. 9.
} 
лял: «Найдется у нас большое количество колхозников, которые приобретут велосипеды» [Гадицкая, Скорик 2009: 261]. Не случайно со временем в обиходе появилась очень хлесткая народная поговорка: «чудо-вещь велосипед: ноги едут, попа - нет». По верному утверждению советских авторов конца 1930-х гг., в колхозной деревне обозначился устойчивый покупательский спрос на новые для села товары, когда «колхозы обзаводятся автомобилями, а колхозники велосипедами» [Наша Родина 1938: 53]. Разумеется, не следует думать, будто все без исключения колхозники имели достаточно средств для покупки велосипеда. Членам слабых в организационно-хозяйственном отношении колхозов, где выдачи на трудодни оставались мизерными, приходилось мечтать не о велосипедах, а о гораздо более необходимых в быту вещах. По меткому замечанию современника, «в одном колхозе нужны велосипеды и патефоны, в другом обувь. Это в зависимости от уровня, который имеет каждый колхоз»1. Так, осенью 1934 г. колхозник (с поистине исторической фамилией - Деникин) из колхоза имени Ильича Вешенского района Азово-Черноморского края жаловался на отсутствие в местном сельпо вожделенного для него велосипеда [Скорик 2009: 435].

Число желающих купить велосипеды неуклонно росло по мере укрепления позиций колхозной системы и повышения материального уровня колхозного крестьянства. По сообщению одного из донских селькоров, не без оснований называвших себя «барометрами деревни» [Панкова-Козочкина 2011: 137], колхозники сельскохозяйственной артели «Роте Фане» Тарасовского района Азово-Черноморского края в 1936 г. купили 30 велосипедов, а в первой половине 1937 г. заказали своему сельпо уже 35 этих индивидуальных транспортных средств ${ }^{2}$. В такой ситуации растущего потребительского спроса в колхозной деревне на велосипеды значительно увеличивались и объемы их продаж. В том же 1937 г. по всему СССР колхозники в общей сложности купили 250 тыс. велосипедов [Хейнман 1939: 68]. По данным органов статистики Ипатовского района Орджоникидзевского (ныне - Ставропольского) края, в 1938 г. в районе продали 125 велосипедов, а в 1939 г. успешно реализовали уже вдвое больше, 250 шт. $^{3}$

Во второй половине 1930-х гг. в советской колхозной деревне сложилась классическая ситуация преобладания спроса над предложением. У сельских жителей появились свободные финансовые средства для сравнительно дорогих покупок, в т.ч. велосипедов. Но промышленность, несмотря на возраставшие объемы производства, не могла в полной мере удовлетворить стремительно возросший и продолжавший расти спрос. В условиях острого дефицита велосипедов в колхозной деревне отдельные жители села пытались спекулировать этим товаром. Как правило, колхозники покупали велосипеды путем продажи магазинам и лавкам потребкооперации своих хлебных излишков. Бывали также случаи, когда в некоторых районах из-за просчетов в планировании поставок появлялся избыток дефицитных промтоваров, в т.ч. велосипедов. Тогда некоторые зажиточные колхозники скупали ходовые вещи с целью их последующей перепродажи по более высокой цене. Подобные спекуляции наблюдались осенью - зимой 1937 г. и в начале 1938 г. в Егорлыкском, Веселовском и ряде других районов Ростовской обл. 4

\footnotetext{
${ }^{1}$ Государственный архив новейшей истории Ставропольского края (ГАНИСК). Ф. 1. Оп. 1. Д. 39. Л. 87.

2 Габаев Н. Сообщение. - Колхознииа. 1937. № 8-9. С. 21.

3 ГАНИСК. Ф. 55. Оп. 2а. Д. 26. Л. 94.

${ }^{4}$ Центр документации новейшей истории Ростовской области (ЦДНИРО). Ф. 9. Оп. 1. Д. 64. Л. 153154.
} 
Значительное преобладание спроса над предложением не позволяло велосипеду войти в быт максимально возможного числа колхозных семей. Далеко не все сельские обыватели в 1930-х гг. могли похвастаться наличием у них своего велосипеда, который в зимнее время за ненадобностью, как это описано у В.Ф. Тендрякова, любители езды на велосипеде могли повесить на вбитые в стену колышки в сенцах, на том самом месте, где в доколхозные времена висели хомуты для лошади ${ }^{1}$. Тем не менее велосипед неуклонно распространялся в колхозной деревне, не исключая Дон, Кубань, Ставрополье. Его можно считать наиболее массовым из новых средств передвижения, появившихся на селе в результате проведения коллективизации в 1930-х гг.

Фото- и кинодокументы позволяют нам вполне уверенно говорить об исключительно обыденном общественном восприятии во второй половине 1930 -х гг. велосипедистов и их двухколесных машин в колхозной деревне. Теперь сельские жители вообще уже не удивлялись, когда вдруг видели, как мимо проехал, «мигая ослепительно спицами, велосипедист» ${ }^{2}$. Многие колхозники сами свободно и часто пользовались велосипедами для различных житейских надобностей, приучали к самостоятельным поездкам на велосипеде своих детей, очень положительно относились к дорожному путешествию на индивидуальном транспортном средстве и довольно буднично рассматривали его в качестве возможности приятного отдыха. К примеру, на одной из фотографий 1937 г. симптоматично запечатлена стахановка, колхозница 1-й полеводческой бригады сельскохозяйственной артели «Роте Фане» Тарасовского района АзовоЧерноморского края Е.И. Классен, которая с нескрываемым удовольствием катается на собственном велосипеде со своей дочерью Гильдой, причем, судя по изображению на журнальном фотоснимке, дочери по возрасту исполнилось где-то 4-5 лет ${ }^{3}$. А вот в сельской пропаганде Армавирского района СевероКавказского края в 1931 г. велосипед ассоциировался с хорошо работающими колхозниками [Гадицкая, Бондарев 2014: 270]. В уже упомянутом нами фильме «Трактористы» обычный дорожный велосипед демонстрируется не реже, чем мотоцикл. Одновременно несколько велосипедов вперемешку с мотоциклами (как мы полагаем, это легкие Л-300 или ИЖ) детально запечатлены рядом со зданием машинно-тракторной станции, из чего можно сделать вывод об их принадлежности трактористам, рабочим и служащим МТС, приехавшим на работу на собственном транспорте. На велосипеде разъезжает «аккуратный почтальон» Харитоша, распевая занятную песенку о важности своей профессии и необходимости велосипеда: «Еду, еду, еду, еду, / Еду, письма раздаю. / Не сходя с велосипеда, / Я с улыбкой всем пою». На велосипеде ездит и главная героиня известной советской музыкальной комедии «Волга-Волга» (1938 г., режиссер Г.В. Александров) письмоносица Дуня Петрова по прозвищу Стрелка, сыгранная блистательной Любовью Орловой.

Итак, в колхозной деревне 1930-х гг. получили распространение новые средства передвижения - мотоциклы и велосипеды, и это стало одним из знаковых результатов индустриализации и коллективизации. Индустриализация создала условия для выпуска техники в значительных объемах, для ее превращения в относительно доступный для широких слоев населения потребительский товар. Коллективизация же сломала деревенскую замкнутость, стимулировала интерес колхозников, и прежде всего сельской молодежи, к новым формам жизнеустройства, сформировала на селе многочисленную когорту

\footnotetext{
1 Тендряков В.Ф. 1955. Не ко двору. - В колхозной деревне: очерки и рассказы. М.: Сельхозгиз. С. 118.

2 Катаев В.П. 1976. Политотдельский дневник: Почти дневник. Изд. 2-е, доп. М.: Советская Россия. C. 117.

3 Габаев Н. Сообщение. - Колхозница. 1937. № 8-9. С. 21.
} 
механизаторов, умевших обращаться с техникой и стремившихся пользоваться ею не только на работе, но и в личном хозяйстве и быту. Механизация сельской повседневности затруднялась целым рядом факторов, в т.ч. ориентацией советской промышленности на первостепенное обслуживание потребностей государства, а не индивидуальных потребителей; невысоким уровнем материально-финансовых доходов основной массы сельского населения; недостаточным числом техники, поступавшей в качестве потребительских товаров в колхозную деревню, и сохранением ее постоянного дефицита в торговых организациях. Тем не менее мотоциклы и велосипеды в 1930-х гг. вполне могли именоваться распространенным и привычным компонентом деревенской действительности. Особенно это справедливо в отношении велосипедов, получивших наивысшую популярность и распространенность в деревне, в т.ч. на Дону, Кубани и Ставрополье.

\title{
Список литературы
}

Гадицкая М.А., Скорик А.П. 2009. Женщины-колхозницы Юга России в 1930-е годы: гендерный потенциал и менталитет. Ростов н/Д: Изд-во СКНЦ ВШ ЮФУ. $324 \mathrm{c}$.

Гадицкая М.А., Бондарев В.А. 2014. Трудовая повседневность колхозной деревни: складывание новых производственных отношений в селах и станицах Юга России 1930-х годов. Новочеркасск: Лик. 284 с.

Наша Родина. 1938. 3-е изд. (под ред. Н. Баранского, П. Поспелова). М.: Госиздат. $117 \mathrm{c.}$

Панкова-Козочкина Т.В. 2011. Работники сельских советов 1920-х годов: номенклатурные подходы большевиков и социальные требования крестьянства (на материалах Юга России). - Российская история. № 6. С. 136-146.

Скорик А.П. 2009. Казачество Юга России в 30-е годы ХХ века: исторические коллизии и опыт преобразований: дис. ... д.и.н. Ставрополь. 540 с.

Хейнман С.А. 1939. Рост благосостояния колхозной деревни. М.: Госиздат. 78 с.

\section{MOTORCYCLES AND BICYCLES AS NEW VEHICLE IN THE DAILY LIFE OF SOUTH-RUSSIAN COLLECTIVE FARMERS OF THE 1930s}

\begin{abstract}
The article reveals one of the iconic plots of the rural everyday life of the period of collective farm construction, when in the village there appeared in mass such vehicles as motorcycles and bicycles, which were not previously characteristic for the region. The author shows quantitative and qualitative indicators of the process of household mechanization among the collective farmers of the South of Russia and describes the brands of domestic motorcycles and bicycles of the 1930s. The article shows the growth of the purchasing power of the rural population, which had the opportunity, in the prevailing order of prices, to purchase motorcycles and bicycles and reveals the attitude of the collective farmers to the new machinery, which increasingly became part of rural everyday life.
\end{abstract}

Keywords: bicycles, deficit, collective farmers, machine operators, motorcycles, daily routine, price of equipment 